\title{
Examining the stability of the long-run relationship between energy and GDP in the presence of an industrialization process
}

\author{
Jacint Balaguer $^{a}$ and Jordi Ripollés ${ }^{b}$ \\ ${ }^{a}$ Department of Economics, Universitat Jaume I (Spain) \\ ${ }^{b}$ Department of Business Economics, Universitat de les Illes Balears (Spain)
}

\begin{abstract}
In this paper we examine the extent to which the relationship between energy consumption and real GDP can be affected by an effective economic development policy based on industrialization. The Spanish Stabilization and Liberalization Plan of 1959 is regarded as a "natural experiment" that is especially interesting for our purposes. To explore long-run causality and possible changes in its direction, we have exploited statistical information for a long period (1900-2008). We applied a movingwindow regression procedure based on the augmented vector autoregressive methodology of Toda and Yamamoto (1995). Causality results are highly sensitive to the industrialization process. For the sub-period preceding the development policy we consistently found greater support for the "conservation hypothesis". This contrasts sharply with the set of results from the data belonging to the subsequent sub-period, where evidence is in favor of the "growth hypothesis".
\end{abstract}

Keywords: Causality, energy consumption, GDP, industrialization, Spain.

JEL classification: C32, O13, O14, Q43. 


\section{Introduction}

Nowadays, there is a growing interest in studying the relationship between energy consumption and economic growth, since knowledge about this issue may be particularly useful as a guide in formulating recommendations for energy and environmental policies. The aim of this paper is to contribute to this burning debate by empirically investigating whether (and, if so, in which direction) the causal relationship between primary energy use and economic growth can be affected by an accelerated industrialization. The successful policy reforms carried out following the Spanish Stabilization and Liberalization Plan (SLP) of 1959 constitute a "natural experiment" that is particularly interesting for our purposes. This development policy marked the end of an era that was characterized by a lack of productive resources and energy restrictions derived from the situation of autarky, and led the way toward a new period where economic openness and liberalization sharply favored an intense process of industrialization and technological modernization.

The direction of the relationship between energy consumption and economic growth can be established through a number of testable hypotheses from the Granger causality principle (Granger, 1969). Thus, the empirical results concerning the basic hypotheses regarding unidirectional causality can be straightforwardly interpreted from the standpoint of policy. These hypotheses are well known in the energy economics literature as the "conservation hypothesis" and the "growth hypothesis". The fulfillment of the former is generally grounded on the existence of causality running from the real Gross Domestic Product (GDP) variable to the use of primary energy. Hence, it would be reasonable to think that policies aimed at preserving the environment by reducing energy consumption would have no notable impact on economic growth. The second of 
these basic hypotheses would be supported by the causality from energy use to GDP, which would indicate that higher energy consumption would be a necessary condition to promote economic growth. Obviously, the existence of a bidirectional causality between both variables of interest is also possible, and would lead to compliance with the socalled "feedback hypothesis". In this case, energy use and economic growth can be thought of as complements to each other. Finally, the non-existence of causality between energy consumption and GDP would provide support for the "neutrality hypothesis", which means that neither conservative nor expansive measures of energy use would have a relevant effect on economic growth.

Since the seminal paper of Kraft and Kraft (1978), a large number of studies have been interested in testing the hypotheses described above by using aggregate data on primary energy consumption. As can be seen from a review of the literature on the topic, the empirical evidence on long-run causality is rather mixed, even when the same country is analyzed. ${ }^{1}$ This apparent lack of consensus is also applicable to the Spanish case. To our knowledge, there are four papers that test the hypotheses using data information from the sixties. Thus, while the recent paper by Narayan and Popp (2012) finds that energy consumption causes real GDP, the results of Climent and Pardo (2007) and Fuinhas and Marques (2012) also support the existence of inverse causality. In contrast, in the paper by Chontanawat et al. (2008) causality is not found between the two variables when Spain is analyzed.

We can think that the existence of heterogeneity of the empirical results in the literature for the same country could reasonably be attributed, at least in part, to some difference in the periods analyzed. In particular, it can be hypothesized that the level of industrial

\footnotetext{
${ }^{1}$ For a survey of the literature on this topic see, for example, Odhiambo (2010), Ozturk (2010), Payne (2010a), and Payne (2010b).
} 
development of a country is, to a greater or lesser extent, progressively changing over time, and empirical results on the causality are sensitive to this sort of changes. Furthermore, differences in results could be attributed to the lack of robustness of some of the methodologies that are applied. On the one hand, this is likely to come from the application of older techniques such as the standard causality methodologies of Granger (1969) or Sims (1972) when time series are non-stationary, which can lead to spurious results (Park and Phillips, 1989; Stock and Watson, 1989). On the other hand, it is likely to come from the application of the Engle-Granger (1987) and Johansen and Juselius (1990) methodologies by using small samples, which can be criticized on the grounds of their low power to test for cointegration between variables (Zapata and Rambaldi, 1997; Harris and Sollis, 2003).

The existing evidence, to our knowledge, offers no guidance on whether economic progress achieved through a process of industrialization in a country can have any significant effect on the relationship between energy and GDP. Instead of comparisons of results throughout a period, many papers are more concerned with comparisons of results across countries. This gap may be due to the fact that the sample time data used for the variables of interest are limited to fairly recent periods that are, in general, too short to allow an empirical answer to be obtained. Next, we exploit time series information for Spain on a large sample period (1900-2008), which covers a sub-period before and after the economic "miracle" resulting from the SLP of 1959. Thus, this time sample will allow us to explore the extent to which an accelerated economic development based on a rapid process of industrialization may affect the possible causality between energy use and GDP. To do so, we will apply the augmented vector autoregressive (VAR) methodology developed in Toda and Yamamoto (1995). The econometric procedure takes into account the possibility of unit roots and avoids the 
problems related to the power and size properties of cointegration tests. This methodology has been widely used in the last few years in the literature on this issue. The recent set of papers by Bowden and Payne (2010), Payne and Taylor (2010), Payne (2011a), Payne (2011b), and Payne (2012) are some interesting examples.

The rest of this work is organized as follows. In the next section we will start by focusing on the policy conditions in the first half of the twentieth century, and then go on to look at the main market-oriented reforms related with the SLP. In Section 3 we will describe both the data and the econometric methodology that were used. In Section 4 we present the results based on moving-window regressions with the aim of exploring possible changes in causality over time. Finally, in Section 5, we will discuss the main conclusions.

\section{An overview of the period analyzed}

The first part of the twentieth century was characterized by a low level of industrialization in which the local production of coal was, in practice, almost the only energy source used. The utilization of this energy source was promoted at this initial stage from 1914 onwards as a result of an increase in external demand deriving from the First World War. This fact gave a certain impulse to the process of industrialization, which was later interrupted by the Spanish Civil War (1936-1939). From then on, under the first two decades of the dictatorial mandate of General Francisco Franco, a high state of interventionism and an autarkic regime were established. One of the cornerstones of the interventionist policy was a plan for the generation of domestic energy resources based on the construction of dams and hydroelectric power plants. However, during this period of interventionism and international isolation, economic development was still relatively low compared to the rest of the neighboring European 
countries, which led the country into a situation of considerable backwardness. The limitation on the amount of foreign currency as well as the administrative obstacles hindering the importation of productive inputs were seen as some of the major causes of bottlenecks curbing the possibilities to grow.

In 1959, given the domestic economic situation, the dictatorial government carried out a set of complementary policy measures for development called the SLP. ${ }^{2}$ The short-run objectives were the stabilization of domestic prices, the liberalization of domestic economic activities, and to boost foreign trade. Interestingly, the reduction of administrative obstacles hindering imports as well as achieving international convertibility of the local currency (peseta) were some of the essential measures applied to promote external trade. An exceptional increase in GDP and energy consumption took place a few years after the implementation of the development plan. Although the incorporation of new local energy sources played a relevant role (i.e., hydro and thermal power plants), the expansion of energy consumption was mainly sustained by the importation of petroleum products. Hence, according to data from the Spanish Ministry of Industry, Energy and Tourism, fuel oil imports increased six-fold in just fifteen years after the introduction of the SLP.

Following the implementation of the SLP, the real GDP grew significantly until 2008 (i.e., when the international economic crisis took place). With few exceptions, such as the short stage of stagnation of energy consumption derived from the world's second oil crisis in 1979, this economic growth was accompanied by a sharp rise in energy consumption. Next, we will explore whether there is a causal relationship between energy use and economic growth, as well as possible changes in each of the stages of the period of interest.

\footnotetext{
${ }^{2}$ A more detailed discussion about political changes can be seen in Fernández-Navarrete (2005).
} 


\section{Data and methodology}

We consider annual data on primary energy consumption and GDP in Spain covering the period from 1900 to 2008 . On the one hand, the energy consumption is expressed in tons of oil equivalent. The primary energy consumption series consisted in the period up to 1972 and was obtained from Sudrià et al. (1995), while the data from 1973 to 2008 was taken from the Spanish Ministry of Industry, Energy and Tourism. On the other hand, GDP is expressed in Euros and in real terms (on the basis of 1995), in accordance with the variation in the domestic consumer price index. The real GDP variable up to 2000 was drawn from Prados de la Escosura (2003), while more recent data were collected from the Bank of Spain's Statistical Bulletin (December, 2011). The evolution of both time series throughout the entire period is shown in Figure 1. As we can see, the extraordinary economic development that started in the early sixties, after the introduction of the SLP, is clearly reflected in the evolution of the real GDP series until the global crisis of 2008. It is also noteworthy that the strong growth of GDP from this time was accompanied by a remarkable growth of primary energy consumption.

\section{[Insert Figure 1 here]}

To analyze the long-run causality between the variables described above we employ the Toda and Yamamoto (1995) approach. This empirical procedure is based on an "augmented" VAR model, regardless of whether the variables are integrated or cointegrated, which guarantees the asymptotic distribution of the usual Wald statistic. Specifically, the procedure requires the estimation of a VAR in levels with a $\left(p+d_{\text {max }}\right)$ order, where $\mathrm{p}$ is the optimal lag length and $\mathrm{d}_{\max }$ represents the maximal order of integration that might occur in the process. Granger non-causality (1969) is then tested on the first $\mathrm{p}$ coefficient matrices by the standard Wald statistic (ignoring the last $\mathrm{d}_{\text {max }}$ 
lagged vectors of the variables). Subsequently, the following bivariate VAR specification is considered: ${ }^{3}$

$$
y_{t}=\alpha+\beta t+\sum_{i=1}^{p+d_{\max }} \gamma_{i} y_{t-i}+u_{t}
$$

where $\mathrm{y}_{\mathrm{t}}=\left(\mathrm{ec}_{\mathrm{t}}, \mathrm{gdp}_{\mathrm{t}}\right)^{\prime}$ is an $n x 1$ vector of endogenous variables composed of the log of primary energy consumption and the $\log$ of GDP, respectively, and $y_{t-i}$ is the corresponding lag term of order i. Additionally, $\gamma_{i}$ is the $(n \times n)$ matrix of autoregressive coefficients of vector $y_{t-i}$ for $\mathrm{i}=1,2, \ldots, \mathrm{p}+\mathrm{d}_{\max } ; \alpha=\left(\alpha_{\mathrm{ec}}, \alpha_{\mathrm{gdp}}\right)$ is the $(\mathrm{nx} 1)$ intercept vector; and $\beta=\left(\beta_{\mathrm{ec}}, \beta_{\mathrm{gdp}}\right)$ refers to the $(\mathrm{nx} 1)$ trend vector. Lastly, $\mathrm{u}_{\mathrm{t}}=$ $\left(u_{e c}, u_{g d p}\right)$ represents the (nx1) vector of error terms, which is assumed to be a whitenoise process.

\section{Causality analysis}

With the aim of identifying possible changes in causality throughout the period analyzed (1900-2008), we implemented moving-window OLS regressions based on Eq. (1). In the estimation process we have introduced an impulse dummy for the Civil War period (1936-39), and a trend dummy for the years following 1936. For each window, the optimal lag length (p) has been selected according to the Akaike Information Criterion (AIC), while the maximal order of integration $\left(\mathrm{d}_{\max }\right)$ was obtained from the unit root tests proposed by Phillips and Perron (1988) (hereinafter: PP), and Elliott et al. (1996) (hereinafter: Dickey-Fuller GLS, DF-GLS). In Table 1 we provide the empirical

\footnotetext{
${ }^{3}$ As in other papers in the literature on this issue (e.g., Fuinhas and Marques, 2012), we acknowledge that some bias from omitted variables could result from the use of simple bivariate models. We are obviously limited to the availability of time series for the analyzed period. However, rather than improving the accuracy of the causality test for a given sub-period, it should be noted that we are more interested in the sensitivity of the results when faced with changes in the degree of industrialization.
} 
results for both unit root tests and long-run causality statistics by considering a window size of 40 observations.

\section{[Insert Table 1 here]}

Results from the PP and DF-GLS unit root tests indicate that the gdp variable is nonstationary in levels but it becomes stationary after taking the first differences (at the 0.01 level of significance). However, both unit root tests produce different results for the stationarity of ec in some cases. Note that Toda and Yamamoto's (1995) causality approach is particularly suitable for application when the variables are integrated of different orders. Then, we are able to safely carry out the procedure after identifying that the maximum order of integration $\mathrm{d}_{\max }$ is 1 for all the windows.

With regard to the long-run causality test, the set of empirical results from the exploratory analysis can be straightforwardly divided into three well-differentiated groups. First, there are those derived from all moving-window regressions based on a sample from the sub-period 1900-1955. From this set of results we can clearly reject the null hypothesis that ec does not cause gdp at least at the 0.10 significance level. Second, empirical results derived from data coming from both this first sub-period and the later one are rather mixed (i.e., non-causality, causality from energy to GDP, and causality from GDP to energy consumption). Third, the empirical results become broadly consistent again when statistical information from the whole sub-period 19612008 is considered. However, in contrast to the first sub-period, we can now reject the null hypothesis that $g d p$ does not cause ec from all moving-window results at the 0.01 significance level.

Additionally, we now perform the Toda and Yamamoto approach (1995) on Eq. (1) by separating the total sample directly into the two sub-periods detected above: one before 
the implementation of the SLP (1900-1955) and the other after (1961-2008). This empirical strategy will allow us to check the robustness of the general empirical outcome obtained previously.

Results of estimates from Eq. (1) for both sub-periods are reported in Table 2. According to the AIC and unit root tests, we can safely assume a VAR with 2 lags $\left(\mathrm{p}=1\right.$ and $\left.\mathrm{d}_{\max }=1\right)$ from 1900 to 1955 and a VAR with 5 lags $\left(\mathrm{p}=3\right.$ and $\left.\mathrm{d}_{\max }=2\right)$ from 1961 to 2008. Moreover, a battery of diagnostic tests indicates that such specifications present the desired econometric properties in both sub-periods. That is, the Jarque-Bera statistic confirms the normality of estimated residuals and the Ramsey RESET test indicates a correct functional form of the equation. We can also reject the presence of autoregressive conditional heteroskedasticity (ARCH) in the error terms. Furthermore, the Breusch-Godfrey LM test statistic suggests the absence of serial correlation, and the stability condition is satisfied, since there are no roots outside the unit circle as we can see in Figure 2.

[Insert Figure 2 here]

Consistently with the results from the moving-window approach, the causality tests from Table 2 for separated time periods suggest that before the SLP of 1959 the direction of causality runs from GDP to energy consumption. That is, in the first part of the last century, empirical evidence is broadly consistent with the "conservation hypothesis". Causality results, however, change throughout the period under review. From the beginning of the sub-period characterized by an accelerated industrialization process to the present, the empirical evidence indicates that causality runs from energy consumption to GDP; that is, evidence of the "conservation hypothesis" clearly disappears in favor of the "growth hypothesis". 
[Insert Table 2 here]

\section{Concluding remarks}

In this paper we have empirically investigated the extent to which the causal relationship between primary energy use and economic growth can be affected by a substantial change in the growth of economic development based on a process of industrialization. To this end, we have exploited a large sample time period for Spanish energy use and GDP, which covers broad sub-periods for before and after the Stabilization and Liberalization Plan implemented in 1959. This constitutes a "natural experiment" for our purposes, since it implies the transition of an economy that was relatively stagnant and with little industrial development to a new situation of accelerated economic development sustained by export-oriented industrialization.

The Granger causality analysis used in our work is based on the augmented VAR methodology developed by Toda and Yamamoto (1995) in a moving-window framework. We found broad consistency of evidence in favor of the "conservation hypothesis" (i.e., unidirectional causality running from GDP to energy consumption) only when data information until 1955 was used. When the sample window corresponds to a mixture of data information from both sub-periods (i.e., before and after the economic reforms), results on causality are rather mixed. Finally, from data belonging to the sub-period after the economic development policy, we found consistent evidence in favor of the fulfillment of the "growth hypothesis" (i.e., causality runs from energy consumption to GDP).

Thus, our results suggest that, although the conservation energy policies are probably adequate in contexts with low economic growth and industrial stagnation, they may not be entirely appropriate in economies with an accelerated industry-based development, 
despite the possible beneficial effect on the environment. In these latter cases, in order to preserve the quality of the environment, we should alternatively consider the possibility of promoting the use of clean energy sources rather than trying to implement policies to reduce energy consumption. However, the existing evidence on the question under study is still too limited and, therefore, further studies need to be conducted to draw final conclusions. We expect that the availability of time data series for other regions which have also undergone an economic development "miracle" some time in their history will help us to improve the knowledge available on this question.

\section{Acknowledgements}

Financial support from the Spanish Ministry of Economy and Competitiveness (ECO2011-28155) and the Generalitat Valenciana (VALI+D, ACIF/2010) are gratefully acknowledged.

\section{References}

Bowden, N., and Payne, J. E. 2010. Sectoral Analysis of the Causal Relationship Between Renewable and Non-Renewable Energy Consumption and Real Output in the U.S. Energy Sources, Part B: Economics, Planning, and Policy 5(4): 400-408.

Breusch, T. S. 1978. Testing for Autocorrelation in Dynamic Linear Models. Australian Economics Papers 17(31): 334-355.

Chontanawat, J., Hunt, L. C., and Pierse, R. 2008. Does Energy Consumption Cause Economic Growth?: Evidence From a Systematic Study of Over 100 Countries. Journal of Policy Modeling 30(2): 209-220. Climent, F., and Pardo, A. 2007. Decoupling Factors on the Energy-Output Linkage: The Spanish Case. Energy Policy 35(1): 552-528.

Elliot, G., Rothenberg, T. J., and Stock, J. H. 1996. Efficient Tests for an Autoregressive Unit Root. Econometrica 64(4): 813-836.

Engle, R.F., and Granger, C. W. J. 1987. Co-integration and Error Correction: Representation, Estimation and Testing. Econometrica 55(2): 251-276.

Fernández-Navarrete, D. 2005. La Política Económica Exterior del Franquismo: Del Aislamiento a la Apertura. Historia Contemporánea 30(1): 49-78.

Fuinhas, J. A., and Marques, A. C. 2012. Energy Consumption and Economic Growth Nexus in Portugal, Italy, Greece, Spain and Turkey: An ARDL Bounds Test Approach (1965-2009). Energy Economics 34(2): 511-517.

Godfrey, L. G. 1978. Testing against General Autoregressive and Moving Average Error Models when the Regressors Include Lagged Dependent Variables. Econometrica 46(6): 1293-1301. 
Granger, C. W. J. 1969. Investigating Causal Relations by Econometric Models and Cross-Spectral Methods. Econometrica 37(3): 424-438.

Harris, R. I. D., and Sollis, R. 2003. Applied Time Series Modelling and Forecasting. John Wiley \& Sons, Chichester.

Johansen, S., and Juselius, K. 1990. Maximum Likelihood Estimation and Inference on Cointegration with Applications to the Demand for Money. Oxford Bulletin of Economics 52(2): 169-210.

Kraft, J., and Kraft, A. 1978. On the Relationship Between Energy and GNP. Journal of Energy and Development 3(2): 401-403.

Odhiambo, N. M. 2010. Energy Consumption, Prices and Economic Growth in Three SSA Countries: A Comparative Study. Energy Policy 38(5): 2463-2469.

Ozturk, I. 2010. A Literature Survey on Energy-Growth Nexus. Energy Policy 38(1): 340-349.

Narayan, P. K., and Popp, S. 2012. The Energy Consumption-Real GDP Nexus Revisited: Empirical Evidence from 93 Countries. Economic Modelling 29(2): 303-308.

Park, J. Y., and Phillips, P. C. B. 1989. Statistical Inference in Regressions with Integrated Processes: Part 2. Econometric Theory 5: 95-131.

Payne, J. E. and Taylor, J. P. 2010. Nuclear Energy Consumption and Economic Growth in the U.S.: An Empirical Note. Energy Sources, Part B: Economics, Planning, and Policy 5(3): 301-307.

Payne, J. E. 2010a. Survey of the International Evidence on the Causal Relationship Between Energy Consumption and Growth. Journal of Economic Studies 37(1): 53-95.

Payne, J. E. 2010b. A Survey of the Electricity Consumption-Growth Literature. Applied Energy 87(3): 723-731.

Payne, J. E. 2011a. On Biomass Energy Consumption and Real Output in the U.S. Energy Sources, Part B: Economics, Planning, and Policy 6(1): 47-52.

Payne, J. E. 2011b. U.S. Disaggregate Fossil Fuel Consumption and Real GDP: An Empirical Note. Energy Sources, Part B: Economics, Planning, and Policy 6(1): 63-68.

Payne, J. E. 2012. The Causal Dynamics between U.S. Renewable Energy Consumption, Output, Emissions, and Oil Prices. Energy Sources, Part B: Economics, Planning, and Policy 7(4): 323-330.

Phillips, P. C. B., and Perron, P. Testing for a Unit Root in Time Series Regression. Biometrika 75(2): 335-346.

Prados de la Escosura, L. 2003. El Progreso Económico de España, 1850-2000. Fundación BBVA, Bilbao. Sims, C. 1972. Money, Income and Causality. American Economic Review 62(4): 540-552.

Stock, J. H., and Watson, M. W. 1989. Interpreting the Evidence in Money-Income Causality. Journal of Econometrics 40(1): 161-182.

Sudrià, C., Martín-Aceña, P., and Simpson, J. 1995. Energy as a Limiting Factor to Growth. The Economic Development of Spain since 1870. Elgar, Edward Publishing, Inc.

Toda, H. Y., and Yamamoto, T. 1995. Statistical Inference in Vector Autoregressions with Possibly Integrated Process. Journal of Econometrics 66(1-2): 225-250.

Zapata, H. O., and Rambaldi, A. N. 1997. Monte Carlo Evidence on Cointegration and Causation. Oxford Bulletin of Economics and Statistics 59(2): 285-298. 
Figure 1. Evolution of energy consumption and real GDP for Spain (1900-2008)

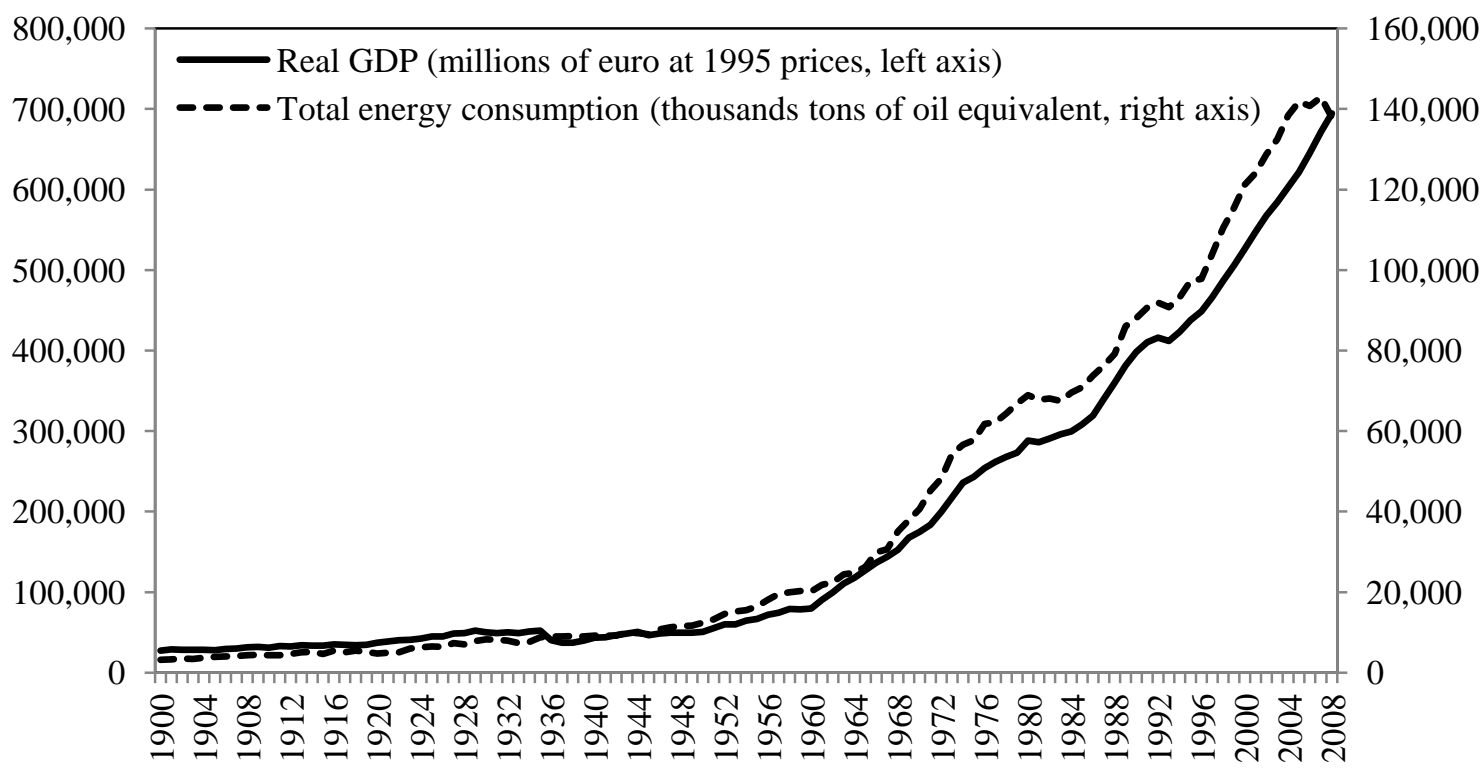

Figure 2. Stability conditions for VAR from Eq. (1)

a) Inverse roots of AR characteristic polynomial VAR(1+1) for sub-period (1900-1955)

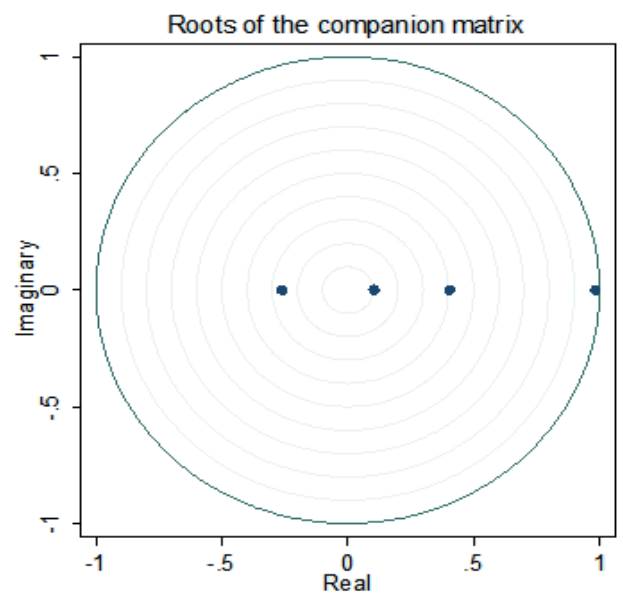

b) Inverse roots of AR characteristic polynomial VAR(3+2) for sub-period (1961-2008)

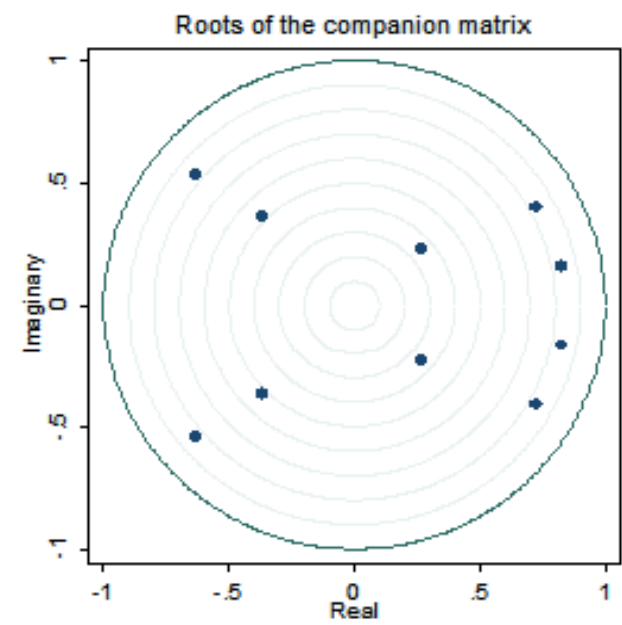


Table 1. Results for unit root tests and long-run causality statistics

\begin{tabular}{|c|c|c|c|c|c|c|c|c|c|c|c|}
\hline \multirow{2}{*}{$\begin{array}{c}\text { Moving } \\
\text { windows }\end{array}$} & \multirow{2}{*}{$\begin{array}{c}\mathrm{AIC} \\
(\mathrm{p}) \\
2\end{array}$} & \multicolumn{2}{|c|}{$\begin{array}{c}\text { PP } \\
(\alpha=10 \%)\end{array}$} & \multicolumn{2}{|c|}{$\begin{array}{l}\text { DF-GLS } \\
(\alpha=10 \%)\end{array}$} & \multirow{2}{*}{$\begin{array}{c}\begin{array}{c}\text { VAR } \\
\left(\mathrm{p}+\mathrm{d}_{\max }\right)\end{array} \\
3\end{array}$} & \multicolumn{2}{|c|}{$\begin{array}{c}\text { Statistics for } H_{0}^{a}: \\
e c \text { does not cause } g d p\end{array}$} & \multicolumn{2}{|c|}{$\begin{array}{l}\text { Statistics for } H_{0}^{b}: g d p \\
\text { does not cause } e c\end{array}$} & \multirow{2}{*}{$\begin{array}{l}\text { Decision } \\
(\alpha=10 \%)\end{array}$} \\
\hline & & $\mathrm{I}(1)$ & $\mathrm{I}(0)$ & $\mathrm{I}(1)$ & $\mathrm{I}(1)$ & & 2.5 & {$[0.287]$} & 12.5 & $[0.002]]^{* * *}$ & \\
\hline 19011941 & 2 & $\mathrm{I}(1)$ & $\mathrm{I}(0)$ & $\mathrm{I}(1)$ & $\mathrm{I}(1)$ & 3 & 3.16 & [0.206] & 9.95 & {$[0.007]^{* * *}$} & $e c \leftarrow g d p$ \\
\hline 19021942 & 2 & $\mathrm{I}(1)$ & $\mathrm{I}(0)$ & $\mathrm{I}(1)$ & $\mathrm{I}(1)$ & 3 & 3.14 & [0.208] & 8.9 & {$[0.012] * *$} & $e c \leftarrow g d p$ \\
\hline 19031943 & 2 & $\mathrm{I}(1)$ & $\mathrm{I}(0)$ & $\mathrm{I}(1)$ & $\mathrm{I}(1)$ & 3 & 3.2 & [0.202] & 8.36 & {$[0.015]^{* *}$} & $e c \leftarrow g d p$ \\
\hline 19041944 & 1 & $\mathrm{I}(1)$ & $\mathrm{I}(0)$ & $\mathrm{I}(1)$ & $\mathrm{I}(1)$ & 2 & 0.24 & [0.623] & 4.88 & {$[0.027]^{* *}$} & $e c \leftarrow g d p$ \\
\hline 19051945 & 1 & $\mathrm{I}(1)$ & $\mathrm{I}(0)$ & $\mathrm{I}(1)$ & $\mathrm{I}(1)$ & 2 & 0 & [0.988] & 3.72 & {$[0.054]^{*}$} & $e c \leftarrow g d p$ \\
\hline 19061946 & 1 & $\mathrm{I}(1)$ & $\mathrm{I}(1)$ & $\mathrm{I}(1)$ & $\mathrm{I}(1)$ & 2 & 0.01 & [0.912] & 3.12 & {$[0.077] *$} & $e c \leftarrow g d p$ \\
\hline 19071947 & 1 & $\mathrm{I}(1)$ & $\mathrm{I}(0)$ & $\mathrm{I}(1)$ & $\mathrm{I}(1)$ & 2 & 0 & [0.956] & 3.11 & {$[0.078] *$} & $e c \leftarrow g d p$ \\
\hline 19081948 & 1 & $\mathrm{I}(1)$ & $\mathrm{I}(0)$ & $\mathrm{I}(1)$ & $\mathrm{I}(1)$ & 2 & 0 & [0.956] & 3.09 & {$[0.079]$ * } & $e c \leftarrow g d p$ \\
\hline 19091949 & 1 & $\mathrm{I}(1)$ & $\mathrm{I}(0)$ & $\mathrm{I}(1)$ & $\mathrm{I}(1)$ & 2 & 0 & [0.975] & 3.13 & {$[0.077]$ * } & $e c \leftarrow g d p$ \\
\hline 19101950 & 1 & $\mathrm{I}(1)$ & $\mathrm{I}(0)$ & $\mathrm{I}(1)$ & $\mathrm{I}(1)$ & 2 & 0 & [0.965] & 3.12 & {$[0.077] *$} & $e c \leftarrow g d p$ \\
\hline 19111951 & 1 & $\mathrm{I}(1)$ & $\mathrm{I}(0)$ & $\mathrm{I}(1)$ & $\mathrm{I}(1)$ & 2 & 0 & [0.953] & 3.13 & {$[0.077]$ * } & $e c \leftarrow g d p$ \\
\hline 19121952 & 1 & $\mathrm{I}(1)$ & $\mathrm{I}(1)$ & $\mathrm{I}(1)$ & $\mathrm{I}(1)$ & 2 & 0.02 & [0.881] & 3.17 & {$[0.075] *$} & $e c \leftarrow g d p$ \\
\hline 19131953 & 1 & $\mathrm{I}(1)$ & $\mathrm{I}(1)$ & $\mathrm{I}(1)$ & $\mathrm{I}(0)$ & 2 & 0.1 & [0.748] & 2.75 & {$[0.097]$ * } & $e c \leftarrow g d p$ \\
\hline 19141954 & 1 & $\mathrm{I}(1)$ & $\mathrm{I}(1)$ & $\mathrm{I}(1)$ & $\mathrm{I}(1)$ & 2 & 0.22 & [0.636] & 3.61 & {$[0.057] *$} & $e c \leftarrow g d p$ \\
\hline 19151955 & 1 & $\mathrm{I}(1)$ & $\mathrm{I}(1)$ & $\mathrm{I}(1)$ & $\mathrm{I}(1)$ & 2 & 0.18 & [0.671] & 3.11 & {$[0.078] *$} & $e c \leftarrow g d p$ \\
\hline 19161956 & 1 & $\mathrm{I}(1)$ & $\mathrm{I}(1)$ & $\mathrm{I}(1)$ & $\mathrm{I}(1)$ & 2 & 0.25 & {$[0.620]$} & 2.01 & {$[0.156]$} & - \\
\hline 19171957 & 1 & $\mathrm{I}(1)$ & $\mathrm{I}(1)$ & $\mathrm{I}(1)$ & $\mathrm{I}(1)$ & 2 & 0.38 & [0.536] & 1.98 & [0.160] & - \\
\hline 19181958 & 1 & $\mathrm{I}(1)$ & $\mathrm{I}(1)$ & $\mathrm{I}(1)$ & $\mathrm{I}(1)$ & 2 & 0.1 & & 29 & & - \\
\hline 19191959 & 1 & $\mathrm{I}(1)$ & $\mathrm{I}(1)$ & $\mathrm{I}(1)$ & $\mathrm{I}(0)$ & 2 & 0.36 & [0.551] & 0.84 & [0.361] & - \\
\hline 19201960 & 1 & $\mathrm{I}(1)$ & $\mathrm{I}(1)$ & $\mathrm{I}(1)$ & $\mathrm{I}(0)$ & 2 & & & 0.26 & {$[0.610]$} & - \\
\hline 19211961 & 1 & $\mathrm{I}(1)$ & $\mathrm{I}(1)$ & $\mathrm{I}(1)$ & $\mathrm{I}(0)$ & 2 & 0.84 & {$[0.360]$} & 0.2 & [0.655] & - \\
\hline 19221962 & 1 & $\mathrm{I}(1)$ & $\mathrm{I}(1)$ & $\mathrm{I}(1)$ & $\mathrm{I}(0)$ & 2 & 1.49 & [0.223] & 0.6 & {$[0.440]$} & - \\
\hline 19231963 & 1 & $\mathrm{I}(1)$ & $\mathrm{I}(1)$ & $\mathrm{I}(1)$ & $\mathrm{I}(1)$ & 2 & 2.08 & [0.149] & 1.29 & [0.257] & - \\
\hline 19241964 & 1 & $\mathrm{I}(1)$ & $\mathrm{I}(1)$ & $\mathrm{I}(1)$ & $\mathrm{I}(1)$ & 2 & 2.15 & [0.142] & 0.53 & [0.465] & - \\
\hline 19251965 & 1 & $\mathrm{I}(1)$ & $\mathrm{I}(1)$ & $\mathrm{I}(1)$ & $\mathrm{I}(1)$ & 2 & 3.67 & {$[0.055]^{*}$} & 0.33 & {$[0.563]$} & $e c \rightarrow g d p$ \\
\hline 19261966 & 1 & $\mathrm{I}(1)$ & $\mathrm{I}(1)$ & $\mathrm{I}(1)$ & $\mathrm{I}(1)$ & 2 & 3.27 & {$[0.070] *$} & 0.56 & [0.454] & $e c \rightarrow g d p$ \\
\hline 19271967 & 1 & $\mathrm{I}(1)$ & $\mathrm{I}(1)$ & $\mathrm{I}(1)$ & $\mathrm{I}(1)$ & 2 & 2.85 & {$[0.091]{ }^{*}$} & 1.41 & [0.234] & $e c \rightarrow g d p$ \\
\hline 19281968 & 1 & $\mathrm{I}(1)$ & $\mathrm{I}(1)$ & $\mathrm{I}(1)$ & $\mathrm{I}(1)$ & 2 & 1.04 & [0.307] & 1.17 & {$[0.280]$} & - \\
\hline 19291969 & 2 & $\mathrm{I}(1)$ & $\mathrm{I}(1)$ & $\mathrm{I}(1)$ & $\mathrm{I}(1)$ & 3 & 2.09 & {$[0.352]$} & 1.62 & [0.444] & - \\
\hline 19301970 & 3 & $\mathrm{I}(1)$ & $\mathrm{I}(1)$ & $\mathrm{I}(1)$ & $\mathrm{I}(1)$ & 4 & 3.91 & {$[0.271]$} & 3.58 & [0.311] & - \\
\hline 19311971 & 3 & $\mathrm{I}(1)$ & $\mathrm{I}(1)$ & $\mathrm{I}(1)$ & $\mathrm{I}(1)$ & 4 & 1.58 & {$[0.665]$} & 2.27 & [0.518] & - \\
\hline 19321972 & 3 & $\mathrm{I}(1)$ & $\mathrm{I}(1)$ & $\mathrm{I}(1)$ & $\mathrm{I}(1)$ & 4 & 2.38 & [0.497] & 2.27 & {$[0.518]$} & - \\
\hline 19331973 & 3 & $\mathrm{I}(1)$ & $\mathrm{I}(1)$ & $\mathrm{I}(1)$ & $\mathrm{I}(1)$ & 4 & 4.13 & [0.248] & 1.97 & [0.579] & - \\
\hline 19341974 & 3 & $\mathrm{I}(1)$ & $\mathrm{I}(1)$ & $\mathrm{I}(1)$ & $\mathrm{I}(1)$ & 4 & 4.44 & {$[0.218]$} & 2.06 & {$[0.561]$} & - \\
\hline 19351975 & 3 & $\mathrm{I}(1)$ & $\mathrm{I}(1)$ & $\mathrm{I}(1)$ & $\mathrm{I}(1)$ & 4 & 4.8 & [0.187] & 1.47 & [0.690] & - \\
\hline 19361976 & 1 & $\mathrm{I}(1)$ & $\mathrm{I}(1)$ & $\mathrm{I}(1)$ & $\mathrm{I}(1)$ & 2 & 0.06 & [0.805] & 0.2 & {$[0.652]$} & - \\
\hline 19371977 & 3 & $\mathrm{I}(1)$ & $\mathrm{I}(1)$ & $\mathrm{I}(1)$ & $\mathrm{I}(1)$ & 4 & 5.3 & {$[0.151]$} & 0.47 & {$[0.926]$} & - \\
\hline 19381978 & 3 & $\mathrm{I}(1)$ & $\mathrm{I}(1)$ & $\mathrm{I}(1)$ & $\mathrm{I}(1)$ & 4 & 4.68 & [0.196] & 2.41 & [0.491] & - \\
\hline 19391979 & 1 & $\mathrm{I}(1)$ & $\mathrm{I}(1)$ & $\mathrm{I}(1)$ & $\mathrm{I}(1)$ & 2 & 0.07 & {$[0.79]$} & 0.21 & [0.645] & - \\
\hline 19401980 & 1 & $\mathrm{I}(1)$ & $\mathrm{I}(1)$ & $\mathrm{I}(1)$ & $\mathrm{I}(1)$ & 2 & 0.07 & [0.789] & 0.35 & {$[0.552]$} & - \\
\hline 19411981 & 3 & $\mathrm{I}(1)$ & $\mathrm{I}(1)$ & $\mathrm{I}(1)$ & $\mathrm{I}(1)$ & 4 & 6.28 & {$[0.099]{ }^{*}$} & 1.52 & {$[0.677]$} & $e c \rightarrow g d p$ \\
\hline
\end{tabular}


Table 1 (continued)

\begin{tabular}{|c|c|c|c|c|c|c|c|c|}
\hline 19421982 & 3 & $\mathrm{I}(1) \mathrm{I}(1) \mathrm{I}(1) \mathrm{I}(0)$ & 4 & 6.16 & {$[0.104]$} & 2.05 & {$[0.561]$} & - \\
\hline 19431983 & 3 & $\mathrm{I}(1) \mathrm{I}(1) \mathrm{I}(1) \mathrm{I}(0)$ & 4 & 5.07 & {$[0.167]$} & 1.94 & {$[0.585]$} & - \\
\hline 19441984 & 3 & $\mathrm{I}(1) \mathrm{I}(1) \mathrm{I}(1) \mathrm{I}(0)$ & 4 & 6.65 & {$[0.084]^{*}$} & 0.61 & [0.894] & $e c \rightarrow g d p$ \\
\hline 19451985 & 2 & $\mathrm{I}(1) \mathrm{I}(1) \mathrm{I}(1) \mathrm{I}(0)$ & 3 & 5.62 & $[0.060]]^{*}$ & 0.77 & {$[0.681]$} & $e c \rightarrow g d p$ \\
\hline 19461986 & 2 & $\mathrm{I}(1) \mathrm{I}(1) \mathrm{I}(1) \mathrm{I}(0)$ & 3 & 2.71 & {$[0.258]$} & 6.09 & {$[0.048]^{* *}$} & $e c \leftarrow g d p$ \\
\hline 19471987 & 2 & $\mathrm{I}(1) \mathrm{I}(1) \mathrm{I}(1) \mathrm{I}(0)$ & 3 & 3.05 & {$[0.217]$} & 4.93 & {$[0.085]^{*}$} & $e c \leftarrow g d p$ \\
\hline 19481988 & 2 & $\mathrm{I}(1) \mathrm{I}(1) \mathrm{I}(1) \mathrm{I}(0)$ & 3 & 3.48 & {$[0.176]$} & 5.09 & {$[0.079] *$} & $e c \leftarrow g d p$ \\
\hline 19491989 & 2 & $\mathrm{I}(1) \mathrm{I}(1) \mathrm{I}(1) \mathrm{I}(0)$ & 3 & 3.03 & {$[0.220]$} & 3.91 & {$[0.141]$} & - \\
\hline 19501990 & 2 & $\mathrm{I}(1) \mathrm{I}(1) \mathrm{I}(1) \mathrm{I}(0)$ & 3 & 2.34 & {$[0.311]$} & 3.98 & [0.137] & - \\
\hline 19511991 & 2 & $\mathrm{I}(1) \mathrm{I}(1) \mathrm{I}(1) \mathrm{I}(0)$ & 3 & 2.77 & {$[0.250]$} & 4.01 & {$[0.135]$} & - \\
\hline 19521992 & 2 & $\mathrm{I}(1) \mathrm{I}(1) \mathrm{I}(1) \mathrm{I}(1)$ & 3 & 2.36 & {$[0.307]$} & 3.79 & {$[0.150]$} & - \\
\hline 19531993 & 2 & $\mathrm{I}(1) \mathrm{I}(1) \mathrm{I}(1) \mathrm{I}(1)$ & 3 & 2.56 & {$[0.279]$} & 4.24 & {$[0.120]$} & - \\
\hline 19541994 & 3 & $\mathrm{I}(1) \mathrm{I}(1) \mathrm{I}(1) \mathrm{I}(1)$ & 4 & 5.67 & [0.129] & 7.2 & {$[0.066]^{*}$} & $e c \leftarrow g d p$ \\
\hline 19551995 & 3 & $\mathrm{I}(1) \mathrm{I}(1) \mathrm{I}(1) \mathrm{I}(1)$ & 4 & 5.92 & {$[0.116]$} & 4.27 & {$[0.233]$} & - \\
\hline 19561996 & 3 & $\mathrm{I}(1) \mathrm{I}(1) \mathrm{I}(1) \mathrm{I}(1)$ & 4 & 4.23 & {$[0.238]$} & 5.06 & [0.167] & - \\
\hline 19571997 & 3 & $\mathrm{I}(1) \mathrm{I}(1) \mathrm{I}(1) \mathrm{I}(1)$ & 4 & 3.29 & [0.349] & 6.14 & {$[0.105]$} & - \\
\hline 19581998 & 3 & $\mathrm{I}(1) \mathrm{I}(1) \mathrm{I}(1) \mathrm{I}(1)$ & 4 & 3.6 & [0.308] & 7.57 & {$[0.056]^{*}$} & $e c \leftarrow g d p$ \\
\hline 19591999 & 3 & $\mathrm{I}(1) \mathrm{I}(1) \mathrm{I}(1) \mathrm{I}(1)$ & 4 & 3.73 & {$[0.292]$} & 3.79 & {$[0.285]$} & - \\
\hline 19602000 & 3 & $\mathrm{I}(1) \mathrm{I}(1) \mathrm{I}(1) \mathrm{I}(1)$ & 4 & 2.97 & [0.397] & 3.77 & [0.287] & - \\
\hline 19612001 & 3 & $\mathrm{I}(1) \mathrm{I}(1) \mathrm{I}(1) \mathrm{I}(1)$ & 4 & 17.85 & $[0.001]]^{* * *}$ & 1.09 & {$[0.779]$} & $e c \rightarrow g d p$ \\
\hline 19622002 & 3 & $\mathrm{I}(1) \mathrm{I}(1) \mathrm{I}(1) \mathrm{I}(1)$ & 4 & 14.61 & {$[0.002]^{* * *}$} & 1.48 & [0.687] & $e c \rightarrow g d p$ \\
\hline 19632003 & 3 & $\mathrm{I}(1) \mathrm{I}(1) \mathrm{I}(1) \mathrm{I}(1)$ & 4 & 15.07 & {$[0.002]^{* * *}$} & 2.96 & [0.398] & $e c \rightarrow g d p$ \\
\hline 19642004 & 3 & $\mathrm{I}(1) \mathrm{I}(1) \mathrm{I}(1) \mathrm{I}(1)$ & 4 & 13.75 & {$[0.003]^{* * *}$} & 1.33 & {$[0.723]$} & $e c \rightarrow g d p$ \\
\hline 19652005 & 3 & $\mathrm{I}(1) \mathrm{I}(1) \mathrm{I}(1) \mathrm{I}(1)$ & 4 & 17.26 & {$[0.001]^{* * *}$} & 2.95 & [0.399] & $e c \rightarrow g d p$ \\
\hline 19662006 & 3 & $\mathrm{I}(1) \mathrm{I}(1) \mathrm{I}(1) \mathrm{I}(1)$ & 4 & 16.53 & {$[0.001]^{* * *}$} & 3.2 & {$[0.362]$} & $e c \rightarrow g d p$ \\
\hline 19672007 & 3 & $\mathrm{I}(1) \mathrm{I}(1) \mathrm{I}(1) \mathrm{I}(1)$ & 4 & 15.80 & {$[0.001]^{* * *}$} & 2.15 & {$[0.543]$} & $e c \rightarrow g d p$ \\
\hline 19682008 & 3 & $\mathrm{I}(1) \mathrm{I}(1) \mathrm{I}(1) \mathrm{I}(1)$ & 4 & 15.24 & {$[0.002]^{* * *}$} & 1.64 & {$[0.651]$} & $e c \rightarrow g d p$ \\
\hline
\end{tabular}

PP and DF-GLS indicate the result of unit root tests proposed by Phillips and Perron (1988), and Elliott et al. (1996), respectively. In this regard, I(0) represents the non-rejection of the null hypothesis of stationarity of the series, whereas I(1) means that variable has one unit root. Lags refer to the optimal lag length according to AIC (p) plus the maximum integration order of the series $\left(\mathrm{d}_{\max }\right)$. The p-values are in brackets and we use ${ }^{* * *},{ }^{* *}$ and ${ }^{*}$ to indicate the rejection of the null hypothesis of non-causality at the $1 \%$, $5 \%$ and $10 \%$ significance levels $(\alpha)$, respectively. We account for the Spanish Civil War in estimations by incorporating an impulse dummy for the time period 1936-39 and a trend dummy for the years after 1936. 
Table 2. Results for unit root tests and long-run causality statistics for separated sub-periods

\begin{tabular}{|c|c|c|c|c|}
\hline & \multicolumn{2}{|c|}{ First sub-period (1900-1955) } & \multicolumn{2}{|c|}{$\begin{array}{l}\text { Second sub-period (1961- } \\
\text { 2008) }\end{array}$} \\
\hline & $e c$ & $g d p$ & \multicolumn{2}{|c|}{$e c \quad g d p$} \\
\hline \multicolumn{5}{|c|}{ Unit root tests and lag length selection } \\
\hline $\mathrm{PP}(\alpha=10 \%)$ & $\mathrm{I}(1)$ & $\mathrm{I}(1)$ & $\mathrm{I}(1)$ & $\mathrm{I}(2)$ \\
\hline DF-GLS $(\alpha=10 \%)$ & $\mathrm{I}(1)$ & $\mathrm{I}(1)$ & $\mathrm{I}(1)$ & $\mathrm{I}(2)$ \\
\hline $\operatorname{AIC}(p)$ & \multicolumn{2}{|c|}{1} & \multicolumn{2}{|c|}{3} \\
\hline $\operatorname{VAR}\left(p+d_{\max }\right)$ & \multicolumn{2}{|c|}{2} & \multicolumn{2}{|c|}{5} \\
\hline \multicolumn{5}{|l|}{ Long-run causality test } \\
\hline $\begin{array}{l}\text { Statistic for } H_{0}^{a}: e c \\
\text { does not cause } g d p\end{array}$ & - & $0.04[0.837]$ & - & $\begin{array}{l}14.07^{* * * *} \\
{[0.003]}\end{array}$ \\
\hline $\begin{array}{l}\text { Statistic for } H_{0}^{b}: g d p \\
\text { does not cause } e c\end{array}$ & $3.88^{* * *}[0.049]$ & - & $1.24[0.743]$ & - \\
\hline $\begin{array}{l}\text { Decision at } 10 \% \\
\text { significance level }\end{array}$ & \multicolumn{2}{|c|}{$e c \leftarrow g d p$} & \multicolumn{2}{|c|}{$e c \rightarrow g d p$} \\
\hline \multicolumn{5}{|l|}{ Diagnostic tests } \\
\hline Ramsey's RESET tes & $1.00[0.403]$ & $0.640[0.594]$ & $1.54[0.223]$ & $0.740[0.535]$ \\
\hline \multirow[t]{9}{*}{ ARCH LM test } & $\begin{array}{l}\{1\} 0.013 \\
{[0.908]}\end{array}$ & $\begin{array}{l}\{1\} 2.677 \\
{[0.102]}\end{array}$ & $\begin{array}{c}\{1\} 0.054 \\
{[0.816]}\end{array}$ & $\begin{array}{l}\{1\} 0.164 \\
{[0.685]}\end{array}$ \\
\hline & $\{2\} 0.036$ & $\{2\} 3.379$ & $\{2\} 0.324$ & $\{2\} 0.153$ \\
\hline & {$[0.982]$} & {$[0.185]$} & {$[0.851]$} & {$[0.926]$} \\
\hline & & & $\{3\} 0.524$ & $\{3\} 1.477$ \\
\hline & & & {$[0.914]$} & {$[0.688]$} \\
\hline & & & $\{4\} 1.077$ & $\{4\} 1.375$ \\
\hline & & & {$[0.898]$} & {$[0.849]$} \\
\hline & & & $\{5\} 4.614$ & $\{5\} 3.024$ \\
\hline & & & {$[0.465]$} & {$[0.696]$} \\
\hline \multirow[t]{4}{*}{ Breusch-Godfrey test } & \multirow{4}{*}{\multicolumn{2}{|c|}{$\begin{array}{l}\{1\} 7.501[0.112] \\
\{2\} 2.660[0.616]\end{array}$}} & \multirow{4}{*}{\multicolumn{2}{|c|}{$\begin{array}{l}\{1\} 3.737[0.443] \\
\{2\} 3.137[0.535] \\
\{3\} 2.267[0.687] \\
\{4\} 5.477[0.242]\end{array}$}} \\
\hline & & & & \\
\hline & & & & \\
\hline & & & & \\
\hline Jarque-Bera test & \multicolumn{2}{|c|}{0.8542} & \multicolumn{2}{|c|}{$1.775[0.777]$} \\
\hline
\end{tabular}

The standard deviations are reported in parenthesis, whereas the p-values are in brackets. We use $^{* * *},{ }^{* *}$ and ${ }^{*}$ to indicate the statistical significance and the rejection of the null hypothesis of non-causality at the $1 \%, 5 \%$ and $10 \%$ significance levels, respectively. We account for the Spanish Civil War in estimations by incorporating an impulse dummy for the time period 193639 and a trend dummy for the years after 1936 . 